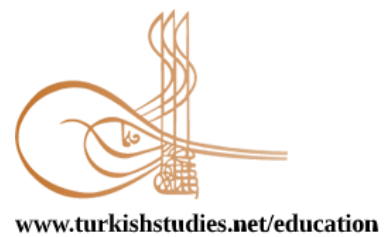

Turkish Studies - Educational Sciences

eISSN: 2667-5609

Research Article / Araştırma Makalesi

\title{
2013 Okul Öncesi Eğitim Programının Çevre Eğitimi Analizi
}

\author{
Analysis of 2013 Preschool Education Program in Terms of Environment Education
}

\author{
Banu Özkan* - Mehmet Nur Tuğluk**
}

\begin{abstract}
Aim of the research is to analyze the gains and indicators included in the Ministry of Education's 2013 Preschool Education Program about environmental education. In the research, screening method used to analyze the programme. The data of the research was collected by the researchers' opinions of 20 academicians working about pre-school education and child development and environmental education with the "Expert Opinion Form" created in line with the gains and indicators included in the program. In the study, the data were collected through the "Expert Opinion Form" prepared by the researchers in the spring term of 2018-2019 academic year, by taking the opinions of 20 instructors working in environmental education from preschool and child development departments. In the expert opinion form 'Gains and indicators of all the areas of development in the Ministry of National Education 2013 Preschool Education Program are included. Experts were asked which of these are related to environmental education. Experts in the form created by the researchers, which are the gains and indicators in this form or which are related to environmental education, are 5 Likert-shaped, "I totally agree", "" I partially agree "," I am indecisive "," I do not agree ", " I disagree at all ". The form contains a total of 406 items, consisting of gains and indicators. The data were analyzed with SPSS 20 package program. In the data analysis, the frequency and percentage distributions of the items in the forms were examined, and the level of acquisition and indicators were shown by tables. When the program is analyzed, according to the opinions of the experts, the pre-school education program does not include gains and indicators for environmental education in the areas of development, motor and language, but gains and indicators for environmental education about social-emotional, cognitive and self care.
\end{abstract}

\section{Structured Abstract: Introduction}

Starting from the moment when human beings seen in this world, affects both the environment in the world and the environment in which it lives. Although environmental education has great importance in education thought since Rousseau and Dewey, its importance was understood in the late 20th and early $21 \mathrm{st}$ centuries.

\footnotetext{
* Dr. Öğr. Üyesi, Kütahya Dumlupınar Üniversitesi, Eğitim Fakültesi, Temel Eğitim Bölümü, Okul Öncesi Eğitimi Assistant Professor, Kütahya Dumlupınar University, Education Faculty, Department of Basic Education, Preschool Education Department$$
\text { ORCID 0000-0001-7844-6115 }
$$

banu.ozkan@dpu.edu.tr

** Dr. Öğr. Üyesi, Yıldız Teknik Üniversitesi, Eğitim Fakültesi, Temel Eğitim Bölümü, Okul Öncesi Eğitimi

Assistant Professor, Ylldiz Technical University, Education Faculty, Department of Basic Education, Preschool Education Department

ORCID 0000-0003-2007-5942

mntugluk@yildiz.edu.tr

Cite as/ Atıf: Özkan, B. \& Tuğluk, M. N. (2020). 2013 Okul öncesi eğitim programının çevre eğitimi analizi. Turkish Studies - Education, 15(3), 1991-1996. https://dx.doi.org/10.29228/TurkishStudies.41743

Received/Geliş: 12 February/Şubat 2020

Accepted/Kabul: 22 June/Haziran 2020

Checked by plagiarism software

Copyright $(\mathrm{C}$ INTAC LTD, Turkey

Published/Yayin: 25 June/Haziran 2020

CC BY-NC 4.0
} 
Preschool period is the period that forms the basis of life. Many behaviors, skills and attitudes are gained in these years. Considering that the education given in this period will leave permanent marks in the life of the child, it is extremely important that environmental education starts in this period (Özkan, 2018).

\section{Method}

In the research, the screening method used to analyze the content of 2013 Pre-School Education Program about environmental education and content analysis was performed.

\section{Conclusion and Suggestion}

When the 2013 Preschool Education Program is analyzed generally, it is seen that the gains and indicators for environmental education are at low levels. In the areas of motor development and language, one of the development areas included in the program, no objectives and gains regarding environmental education have been found. It is seen that there is a limited number of other development areas. In line with the findings of the research, for the researches to be conducted;

- The concept of "environmental education" can be included in program arrangements with different goals, achievements, concepts and certain days and weeks.

- Environmental training seminars can be organized for preschool educators.

Keywords: Preschool Education, Preschool Education Program, Environmental Education, Gains and Indicators, Child Development

Öz: Bu araştırma, Milli Eğitim Bakanlığı 2013 Okul Öncesi Eğitim Programındaki kazanım ve göstergeleri çevre eğitimi açısından incelemeyi amaçlamaktadır. Bu doğrultuda, Okul Öncesi Eğitim Programının çevre eğitimi bakımından içerik analizi yapılmıştır. Araştırmada veriler 2018-2019 eğitim öğretim yılı bahar döneminde, araştırmacılar tarafından hazırlanan "Uzman Görüş Formu” ile okul öncesi ve çocuk gelişimi bölümlerinden, çevre eğitimi çalışan 20 öğretim elemanının görüşlerinin alınması yoluyla toplanmıştır. Uzman görüş formunda 'Milli Eğitim Bakanlığı 2013 Okul Öncesi Eğitim Programındaki tüm gelişim alanlarına ait kazanım ve göstergeler yer almıştır. Uzmanlara bunlardan hangilerinin çevre eğitimi ile ilgili olduğu sorulmuştur. Uzmanlar bu formda yer alan kazanım ve göstergelerin hangisi ya da hangilerinin çevre eğitimi ile ilgili olduğunu araştırmacılar tarafından oluşturulan formda, 5'li Likert şeklindeki, "tamamen katılıyorum", 'kısmen katılıyorum", "kararsızım”, "katılmıyorum", 'hiç katılmıyorum", şeklindeki tabloya işaretlemiştir. Formda, kazanım ve göstergelerden oluşan toplam 406 madde bulunmaktadır. Veriler SPSS 20 paket programı ile analiz edilmiştir. Veri analizinde, formlarda yer alan maddelerin frekans ve yüzde dağılımlarına bakılmış, kazanım ve göstergelerin yer alma düzeyleri tablolaştırılmıştır. Program kazanım göstergeler açısından incelendiğinde, uzmanlara göre gelişim alanlarındaki kazanımlarda, motor ve dil alanlarında çevre eğitimine yönelik yönelik kazanım ve göstergelerin yer almadığı ancak sosyal-duygusal, bilişsel ve özbakım becerileri alanlarında çevre eğitimine ilişkin kazanım ve göstergelerin mevcut olduğu görülmektedir.

Anahtar Kelimeler: Okul Öncesi Eğitim, Okul Öncesi Eğitimi Programı, Çevre Eğitimi, Kazanım ve Göstergeler, Çocuk Gelişimi

\section{Giriş}

İnsanoğlunun bu dünyada görüldüğü andan başlayarak hem dünyadaki çevresel koșullardan etkilendiği, hem de içinde yaşadığ 1 çevreyi etkilediği söylenebilir. Çevre eğitiminin Rousseau ve Dewey'den bu yana eğitim düşüncesinde büyük yeri olmasına rağmen önemi, 20. yüzyıl sonu ve 21. yüzyıl başlarında anlaşıllmıştır.

Okul öncesi dönem yaşamın temelini oluşturan dönemdir. Birçok davranış, beceri ve tutum bu yıllarda kazanılmaktadır. Bu dönemde verilen eğitimin çocuğun hayatında önemli izler bırakacağı düşünüldüğünde, çevre eğitiminin de bu dönemde başlaması son derece önemlidir (Özkan, 2018). Keller (2005)'e göre, çocuklar kendi çevrelerini keşfederken, yeni bilgiler geliştirir ve daha önce elde ettikleri bilgiler ile arasında ilişki kurarlar. Doğa, çocuklara doğayla etkileşim 
kurdukları etkinliklerde yeni kavramlar geliştirmeleri için çeşitli firsatlar sunar (Akt, Zurek, Torquati ve Acar, 2014). Son y1llarda birçok ülkede okullarda çevre eğitimine yer verilmektedir. (Stokes vd, 2001).

Ayvaz ve diğerleri (1999)‘a göre

* Çevre eğitimi kişinin kendisi için önemli olup huzur içinde yaşamayı sağlamaktadır ancak günümüzde çocuklar doğal çevreden uzaklaşmaktadır.

* Dünya giderek insan etkileri ile bozulmaktadır. Bununla birlikte, ekolojik problemlere çözüm üretecek genç nesillere gereksinim vardır.

* Tabiat, bir model olması nedeniyle okul öncesi programlarında önemli bir yer tutar. Çocukların bazı bilimsel süreç becerileri doğayla etkileşimleri sırasında gelişmektedir.

Buradan hareketle, erken çocukluk döneminin çevre eğitimine başlamak için en doğru zaman olduğu düşüncesiyle, okul öncesi eğitimde görev yapan öğretmenlerinin günlük ve aylık eğitim akışlarını hazırladığı ve rehber kitapları olan programın çevre eğitimi açısından analiz edilmesi araştırmanın problemini oluşturmaktadır.

Literatür incelendiğinde Gülay ve Ekici (2010) yılında, MEB 2002 Okul Öncesi Programını çevre eğitimi açısından incelemişler ancak 2013 de güncellenen programın çevre eğitimi açısından analizi ile ilgili bir çalışmaya rastlanmamıştır. Bu anlamda, çalışmanın okul öncesi eğitim alanı için önemli olduğu söylenebilir.

\section{Yöntem}

Araştırmada, MEB 2013 Okul Öncesi Eğitimi Programı'nın çevre eğitimi yönünden içerik analizi yapılmıştır. İçerik analizi, sözel, yazılı ve diğer materyallerin içerdiği mesajı, anlam ve dilbilgisi açısından nesnel ve sistematik olarak sınıflandırma, sayılara dönüştürme ve çıkarımda bulunma vasıtasıyla sosyal gerçeği araştıran bir yaklaşımdır (Büyüköztürk vd, 2008).

Çalışma Grubu: Okul öncesi eğitim ve çocuk gelişimi bölümlerinde görev yapan ve çevre eğitimi ile ilgli çalışmaları bulunan toplam 20 öğretim elemanı çalışmaya katılmıştır.

Veri Toplama Aracı: Veri toplama aracı olarak 2013 okul öncesi programındaki kazanım ve göstergeleri içeren bir form kullanılmıştır. Uzmanlar bu formda yer alan kazanım ve göstergelerin hangisi ya da hangilerinin çevre eğitimi ile ilgili olduğunu araştırmacılar tarafindan oluşturulan formda, 5'li Likert şeklindeki, "tamamen katılıyorum", 'kısmen katılıyorum", "kararsızım", "katılmıyorum",',hiç katılmıyorum", şeklindeki tabloya işaretlemiştir. Formda, kazanım ve göstergelerden oluşan toplam 406 madde bulunmaktadır.

Verilerin Toplanması: Verilerin toplanması amacıyla hazırlanan 5 li likert türünde maddeleştirilmiş kazanım ve göstergelerin yer aldığ ‘ "Uzman Görüş Formu", okul öncesi eğitim ve çocuk gelişimi bölümlerinde görev yapan ve erken çocukluk döneminde çevre ile ilgili çalışmaları olan çalışan 20 öğretim elemanına verilerek, görüşleri alınmıştır.

Verilerin Analizi: Veriler SPSS 20 paket programı ile analiz edilmiştir. Veri analizinde, formlarda yer alan maddelerin frekans ve yüzde dağılımlarına bakılmış, kazanım ve göstergelerin yer alma düzeyleri tablolaştırılmıştır.

\section{Bulgular}

Tablo 1: 2013 OÖEP da Motor Gelişim Alanındaki Kazanım ve Göstergelerin Çevre Eğitimine Yönelik Uzman Görüşleri

\begin{tabular}{|l|l|l|}
\hline Motor Gelişim & Kazanım & Gösterge \\
\hline Cevre eğitimi & 0 & 0 \\
\hline Toplam & 5 & 70 \\
\hline
\end{tabular}


Tablo 1 incelendiğinde; uzman görüşlerine göre motor alanda çevre eğitimi ile ilişkili kazanım ve gösterge yer almamaktadır. Başka bir ifadeyle, araştırmaya katılan uzmanlar bu alanda bir kazanım ya da gösterge olmadığını belirtmiştir.

Tablo 2: 2013 OÖEP da Bilişsel Gelişim Alanındaki Kazanım ve Göstergelerin Çevre Eğitimine Yönelik Uzman Görüșleri

\begin{tabular}{|c|c|c|}
\hline Bilişsel & Kazanım & Gösterge \\
\hline & $\begin{array}{l}\text { Kazanım 5. Nesne ya da varlıkları } \\
\text { gözlemler. }\end{array}$ & $\begin{array}{l}\text { Göstergeleri: Nesne/varlığın } \\
\text { Adını } \\
\text { rengini, } \\
\text { şeklini, } \\
\text { büyüklüğünü, } \\
\text { uzunluğunu, } \\
\text { dokusunu, } \\
\text { sesini, } \\
\text { kokusunu, } \\
\text { yapıldığı malzemeyi, } \\
\text { tadını, } \\
\text { miktarını } \\
\text { kullanım amaçlarını söyler. }\end{array}$ \\
\hline & $\begin{array}{l}\text { Kazanım 17. Neden-sonuç ilişkisi } \\
\text { kurar. }\end{array}$ & $\begin{array}{l}\text { Göstergeleri: Bir olayın olası nedenlerini söyler. } \\
\text { Bir olayın olası sonuçlarını söyler }\end{array}$ \\
\hline & $\begin{array}{l}\text { Kazanım 19. Problem durumlarına } \\
\text { çözüm üretir. }\end{array}$ & $\begin{array}{l}\text { Göstergeleri: Problemi söyler. } \\
\text { Probleme çeşitli çözüm yolları } \\
\text { önerir. } \\
\text { Çözüm yollarından birini seçer. } \\
\text { Seçtiği çözüm yolunun gerekçesini söyler. Seçtiği } \\
\text { çözüm yolunu dener. } \\
\text { Çözüme ulaşamadığı zaman yeni bir çözüm yolu } \\
\text { seçer. } \\
\text { Probleme yaratıcı çözüm yolları önerir. }\end{array}$ \\
\hline Sayı & 3 & 21 \\
\hline Toplam: & 21 & 113 \\
\hline
\end{tabular}

Tablo 2 incelendiğinde; uzmanlara göre bilişsel alanda çevre eğitimine yönelik 3 kazanım ve 21 gösterge yer almaktadır.

Tablo 3: 2013 OÖEP da Sosyal-Duygusal Gelişim Alanındaki Kazanımların ve Göstergelerin Çevre Eğitimine Yönelik Uzman Görüşleri

\begin{tabular}{|l|l|l|}
\hline $\begin{array}{l}\text { Sosyal duygusal } \\
\text { gelişim }\end{array}$ & \multicolumn{1}{|c|}{ Kazanım } & \multicolumn{1}{c|}{ Gösterge } \\
\hline & $\begin{array}{l}\text { Kazanım 10. Sorumlulukların } \\
\text { yerine getirir. }\end{array}$ & $\begin{array}{l}\text { Sorumluluk almaya istekli olduğunu gösterir. } \\
\text { Üstlendiği sorumluluğu yerine getirir. Sorumluluklar } \\
\text { yerine getirilmediğinde olası sonuçları söyler. }\end{array}$ \\
\hline & $\begin{array}{l}\text { Kazanım 13. Estetik değerleri } \\
\text { korur. }\end{array}$ & $\begin{array}{l}\text { Cevresinde gördüğü güzel ve rahatsı edici durumları } \\
\text { söyler. } \\
\text { Çevresini farklı biçimlerde düzenler. Çevredeki } \\
\text { güzelliklere değer verir. }\end{array}$ \\
\hline Sayı & $\mathbf{2}$ & \multicolumn{1}{|c|}{$\mathbf{6}$} \\
\hline Toplam: & $\mathbf{5 3}$ & \multicolumn{1}{|c|}{$\mathbf{5 3}$} \\
\hline
\end{tabular}

Tablo 3 incelendiğinde; uzman görüşlerine göre bilişsel alanda çevre eğitimine yönelik 2 kazanım ve 6 gösterge yer almaktadır. 
Tablo 4: 2013 OÖEP da Dil Gelişim Alanındaki Kazanım ve Göstergelerin Çevre Eğitimine Yönelik Uzman Görüşleri

\begin{tabular}{|l|l|l|}
\hline Dil Gelişimi & Kazanım & Gösterge \\
\hline Çevre eğitimi & 0 & 0 \\
\hline Toplam & 12 & 72 \\
\hline
\end{tabular}

Tablo 4 incelendiğinde; uzman görüşlerine göre dil alanda çevre eğitimine yönelik kazanım ve gösterge yer almamaktadır.

Tablo 5: 2013 OÖEP da Özbakım Alanındaki Kazanım ve Göstergelerin Çevre Eğitimine Yönelik Uzman Görüşlerinin Dağılımı

\begin{tabular}{|l|l|l|}
\hline Özbakım & Kazanım & Gösterge \\
\hline & $\begin{array}{l}\text { Kazanım 3. Yaşam alanlarında gerekli } \\
\text { düzenlemeler yapar. }\end{array}$ & $\begin{array}{l}\text { Göstergeleri: } \\
\text { Ev ve okuldaki eşyaları temiz ve özenle } \\
\text { kullanır }\end{array}$ \\
\hline & $\begin{array}{l}\text { Kazanım 6. Günlük yaşam becerileri için } \\
\text { gerekli araç ve gereçleri kullanır. }\end{array}$ & $\begin{array}{l}\text { Göstergeleri: } \\
\text { Çevre temizliği ile ilgili araç ve gereçleri } \\
\text { kullanır. }\end{array}$ \\
\hline & $\begin{array}{l}\text { Kazanım 7. Kendini tehlikelerden ve vöstergeleri: Tehlikeli olan durumları } \\
\text { kazalardan korur. } \\
\text { söyler. } \\
\text { Kendini tehlikelerden ve kazalardan } \\
\text { korumak için yapıllması gerekenleri söyler. } \\
\text { Temel güvenlik kurallarını bilir. }\end{array}$ \\
\hline Sayı & $\mathbf{3}$ & \multicolumn{1}{c|}{$\mathbf{5}$} \\
\hline Toplam: & $\mathbf{3 5}$ \\
\hline
\end{tabular}

Tablo 5 incelendiğinde; uzmanlara göre özbakım alanında çevre eğitimine yönelik 3 kazanım ve 5 gösterge yer almaktadır.

\section{Tartışma ve Sonuçlar}

2013 MEB Okul Öncesi Eğitim Programı genel olarak incelendiğinde, çevre eğitimine yönelik, kazanım ve göstergelerin yetersiz olduğu belirlenmiştir. Programda yer alan gelişim alanlarından motor gelişim ve dil gelişimi alanlarında çevre ile ilgili kazanım ya da göstergeye rastlanmamıştır. Diğer gelişim alanlarında da kazanım ve göstergelerin yetersiz olduğu görülmektedir. Literatürde okul öncesi eğitim programlarının incelendiği çeşitli araştırmalar mevcuttur. Akçay (2006) yaptığı çalışmada, Almanya, İsviçre gibi bazı ülkelerin okul öncesi eğitim programlarındaki çevre eğitimi etkinlik yüzdesinin Türkiye'den fazla olduğu sonucuna ulaşmıştır. Kanada ve $\mathrm{ABD}$ ise Türkiyeden daha düşük seviyede etkinliğe yer vermektedir. Bu araştırmanın sonucuna göre, Türkiye son sıralarda olmasa da, birçok ülkenin gerisindedir. Buhan (2006) ise araştırmasında, çevre koruma, kirliliği önleme gibi bazı davranışlarla ilgili, katı atıkların toplanıp ve geri dönüştürülmesi gibi bazı alanlarda okul öncesi eğitim programına eklemeler yapılmasının gerekliliğini belirtmiştir. Gülay ve Ekici (2009) yılında MEB 2006 Okul Öncesi Eğitim Programını çevre eğitimi açısından incelemiş̧ler, psikomotor ve dil alanlarında çevre eğitimine yönelik amaç ve kazanım bulunmadığı sonucuna ulaşmışlardır. Bizim araştırmamızda, 2006 yılından sonra güncellenen 2013 Okul Öncesi Eğitim Programı incelenmiştir. Ancak görülmektedir ki, motor ve dil gelişim alanlarındaki kazanımlarda 2006 ve 2013 programları arasında çevre eğitimi ile ilgili bir fark yoktur. 2006 Okul Öncesi Programı 2013 yılında güncellenmiştir. Araştırmada elde ettiğimiz sonuçlar Gülay ve Ekici (2009) un bulgularına benzerdir.

Sürdürülebilirlik ve permakültür gibi kavramlar son yıllarda dikkat çekmeye başlamıştır. Çevre eğitiminin öneminin anlaşılmasıyla birlikte, tüketim alışkanlıkları değişmiş, sürdürülebilir davranışlar gelişmiş, beslenme ve yaşam tarzlarımız farklılaşmıştır. Elbette bu değişim eğitime de 
yansımaktadır. Eğitimin her kademesinde çevre eğitimi ile ilgili dersler okutulmaktadır. Okul Öncesi Öğretmenliği Lisans Programında seçmeli ders olarak bazı üniversitelerde okutulan 'Çevre Eğitimi' dersleri 2018 de YÖK tarafindan güncellenen lisans programında ''Erken Çocuklukta Çevre Eğitimi'" ismiyle zorunlu bir ders olarak yer almaya başlamıştır. Tüm bu gelişmeler çevre eğitimine verilen önemin arttı̆̆ını göstermektedir. Ancak yine de okul öncesi eğitm programında çevre eğitimine yönelik bazı değişiklikler yapılması önerilebilr.

Araştırmadan elde edilen bulgular doğrultusunda;

- Program düzenlemelerinde "ç̧evre eğitimi" ile ilgili farklı kazanım ve göstergelere daha fazla yer verilmesi önerilmektedir.

- $\quad$ Okul öncesi eğitimcilere yönelik çevre eğitimi (çocuklarda çevre bilinci oluşturmak, sürdürülebilir yaşam, permakültür gibi) konularda eğitim seminerleri düzenlenebilir.

- $\quad$ Çevre eğitiminin erken yaşta başlamasının önemi düşünüldüğünde, anne baba ve eğitimcilerin bu alandaki becerilerin çocuklara kazandırılmasında çocuklara rol model olması önerilebilir.

\section{Kaynakça}

Akçay, İ. (2006). Farklı ülkelerde okul öncesi öğrencilerine yönelik çevre eğitimi. Yayımlanmamış Yüksek Lisans Tezi. Uludağ Üniversitesi, Sosyal Bilimler Enstitüsü.

Ayvaz, Z., Öztürk, M., Balc1, A., Uzunoğlu, S., Noyan, Ö. F., Pazarlığlu, M. V., Baldemir, E., Başlar, S., Doğan, Y., Gökalp, M. F., Semenderoğlu, A. ve Bakaç, M. (1999). Okul öncesi çevre eğitimi. İzmir: Çevre Eğitimi ve Araştırma Vakfı (ÇevKor: Çevre Eğitimi Merkezi Yayınlar1: 6).

Buhan, B. (2006). Okul öncesinde görev yapan öğretmenlerin çevre bilinci ve bu okullardaki çevre eğitiminin araştırılması. Marmara Üniversitesi Eğitim Bilimleri Enstitüsü. Yayımlanmamış Yüksek Lisans Tezi.

Büyüköztürk Ş., Çakmak, E. K., Akgün, Ö. E., Karadeniz, Ş. \& Demirel, F. (2008). Bilimsel Araştırma Yöntemleri. Pegem-A Yayıncılık.

Gülay, H., Ekici, G. (2009). MEB Okul Öncesi Eğitim Programının Çevre Eğitimi Açısından Analizi. Türk Fen Ĕ̈itimi Dergisi, 7(1), 74-84.

Özkan, B. (2018). Erken Çocuklukta Sürdürülebilirlik ve Çevre Eğitimi. Erken Çocuklukta Fen Eğitimi içinde (Ed: Mustafa Sami TOPÇU, Banu ÖZKAN). Efe Akademi Yyaıncılık.

Stokes, E. Edge, A., West, A. (2001). Environmental education in the educational systems of the European Union. Commissioned by the Environment Directorate-General of the European Commission.

Zurek, A., Torquati, J., Acar, İ. (2014). Scaffolding as a Tool for Environmental Education in Early Childhood. International Journal of Early Childhood Environmental Education, 2(1), 27 57. 